(2) Open Access Full Text Article

\title{
A retrospective study on the prognostic value of preoperative neutrophil/lymphocyte ratio in patients with primary small-cell carcinoma of the esophagus
}

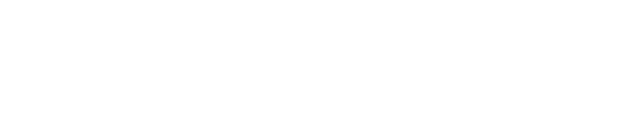

Yan Wang

Jun Feng Liu

Department of Thoracic Surgery, The Fourth Hospital of Hebei Medical University, Shijiazhuang, China
Correspondence: Jun Feng Liu Department of Thoracic Surgery, The Fourth Hospital of Hebei Medical University, I2, Jiankang Road, Shijiazhuang, Hebei Province, China Tel +863II86095353 Email 20504744@qq.com
Introduction: There is increasing evidence that systemic inflammation influences the prognosis in patients with malignant tumors. The aim of this research was to investigate the prognostic value of neutrophil/lymphocyte ratio (NLR) in patients with primary small-cell carcinoma of the esophagus.

Methods: This study retrospectively analyzed 129 patients with primary small-cell carcinoma of the esophagus who underwent esophagectomy in The Fourth Hospital of Hebei Medical University between January 2008 and December 2010. NLRs were calculated by using the following formula: peripheral neutrophil count/lymphocyte count $\left(10^{9} / \mathrm{L}\right)$. Correlations of NLR with other clinicopathologic data and prognosis were analyzed. The survival rate was calculated by Kaplan-Meier analysis. The differences between groups were compared by using the log-rank test. Cox regression was used to analyze the factors that may affect the survival of the patients.

Results: The survival rate was found to be related to tumor stage, tumor location, nodal metastasis, TNM stage, histology, adjuvant therapy, and NLR (all $P<0.05$ ). High-NLR group had significantly poorer survival than low-NLR group (1-, 3-, and 5-year survival rates: $46.6 \%$ vs $57.1 \%, 21.9 \%$ vs $50.0 \%$, and $5.5 \%$ vs $23.2 \%$, respectively, $P=0.002$ ). NLR was identified as an independent prognostic factor for patients with primary small-cell carcinoma of the esophagus.

Conclusion: NLR is a valuable clinical marker in preoperative estimation as well as prognosis prediction for patients with primary small-cell carcinoma of the esophagus.

Keywords: neutrophil/lymphocyte ratio, primary small-cell carcinoma of the esophagus, surgery, prognosis

\section{Introduction}

Primary small-cell carcinoma of the esophagus (SCCE) is an extremely rare disease, representing only $0.005 \%-4 \%$ of esophageal cancers (ECs) and $0.004 \%-4.6 \%$ of all gastrointestinal neuroendocrine neoplasms. ${ }^{1,2}$ On account of its rarity, a standard treatment has not yet been established. ${ }^{2}$ Patients with SCCE have been treated with surgery, chemotherapy, and radiotherapy, alone or in combination. ${ }^{1}$ However, the outcome for SCCE remains grim due to a poor therapeutic response and a high rate of disease recurrence. ${ }^{3}$

Recently, there is increasing evidence that systemic inflammatory response plays an important role in postoperative survival in patients with gastrointestinal cancers. ${ }^{4-6}$ Previous studies have shown that pretreatment neutrophil/lymphocyte ratio (NLR), 
as an index of systemic inflammation, influenced the prognosis in patients with various cancers, including esophageal squamous cell carcinoma. ${ }^{7-9}$ The present study investigated the prognostic value of NLR in patients with SCCE.

\section{Methods}

\section{Patients}

From January 2008 to December 2010, a total of 4,141 patients received esophagectomy for EC at the Department of Thoracic Surgery, Tumor Hospital of Hebei (Shijiazhuang, China). The inclusion criteria were as follows: 1) SCCE confirmed by histopathology, 2) surgery with curative esophagectomy, 3) surgery not preceded by neoadjuvant therapy, and 4) preoperative NLRs obtained before esophagectomy within 1 week. The exclusion criteria were as follows: 1) non-SCCE, 2) previous or coexisting cancers other than SCCE, 3) previous chemotherapy and/or radiotherapy, 4) active concomitant infection within 1 week, and 5) distant metastasis. Finally, 129 patients were found to be eligible for this study. The following data of all the patients were collected: age, gender, laboratory examination, tumor stage and location, nodal metastasis, histology, and other miscellaneous characteristics on the basis of the medical records. Ethical approval from the ethical committee of the Tumor Hospital of Hebei, Shijiazhuang, China, was obtained. Informed consent was obtained from all individual participants included in the study.

\section{Follow-up}

All patients received a standardized 3-month interval follow-up for the first year after operation, 6-month interval follow-up in the next 2 years, and yearly follow-up thereafter. Medical history, physical examination, and computed tomography of the chest were recorded during the follow-up. The last follow-up date was December 31, 2015.

\section{Statistical analysis}

All statistical calculations were performed by using SPSS 17.0 for Windows (SPSS Inc., Chicago, IL, USA). The relationship between NLR and other clinicopathologic factors was analyzed by Pearson's chi-squared test. Survival rate was analyzed by Kaplan-Meier analysis with log-rank test. A multivariate Cox proportional hazards regression model with the enter method was constructed to identify independent prognostic factors. A 95\% confidence interval (CI) was used to quantify the relationship between survival time and each independent factor. All $P$-values were two-sided in the tests. $P<0.05$ was considered statistically significant. The Akaike information criterion (AIC) was used to identify the statistical model. ${ }^{10}$ AIC was defined as $\mathrm{AIC}=-2 \log ($ maximum likelihood $)+2 \times$ (number of parameters in the model). A smaller AIC value indicates a more desirable model for predicting outcomes.

\section{Results}

More than 4,000 patients with pathologically confirmed malignant tumors of the esophagus after surgery were recruited. Among these patients, 138 patients were confirmed with SCCE, 133 patients had received no neoadjuvant therapy prior to esophagectomy, and 129 patients had complete clinical data including age, gender, histology, tumor location and stage, nodal metastasis, complete blood count, and treatment. Finally, 129 patients were included in the study. The study flowchart is shown in Figure 1. The median age for the patients was 60 years (range: 39-78 years). Eightyfive $(65.9 \%)$ of the patients were men. Forty-eight $(37.2 \%)$ patients had stage I, 54 (41.9\%) had stage II, and 27 (20.9\%) had stage III SCCE. At the end of this study (December 31, 2015), 113 (87.6\%) patients died. The median follow-up duration for those who were still alive at the final follow-up was 67.5 months (range: 60-81 months).

All the eligible patients underwent radical esophagectomy. One hundred and eighteen patients underwent one incision via left thoracic approach. Three patients were treated by thoracotomy on the right side and intrathoracic gastric reconstruction. Lesions of the upper third were treated by cervical anastomosis. Along with esophagectomy, lymphadenectomy was performed, including the subcarinal, paraesophageal, pulmonary ligament, diaphragmatic, and the origin of the left gastric artery. The cervical lymph node dissection was performed only if abnormality was confirmed by preoperative evaluation. All of the patients were restaged according to the seventh edition of the American Joint Committee on Cancer (AJCC) Cancer Staging Manual. ${ }^{11}$ All patients received adjuvant chemotherapy. Forty-nine (38.0\%) patients received adjuvant chemoradiotherapy. Among these patients, $19(38.8 \%)$ patients received conventional radiotherapy, $16(32.7 \%)$ patients received three-dimensional conformal radiotherapy, and the remaining 14 (28.5\%) patients received an intensity-modulated radiation therapy.

Receiver operating characteristic (ROC) curves for overall survival (OS) prediction were plotted to verify the optimum cutoff point for NLR. The area under the ROC curve was 0.704 (95\% CI: 0.589-0.818) and, according to the ROC curve, the best cutoff value of NLR was 2.97, with a sensitivity of $61.1 \%$ and a specificity of $62.5 \%$. The patients were then divided into two groups according to NLR: $56(43.4 \%)$ patients with NLR $<2.97$ and 73 (56.6\%) patients with NLR $\geq 2.97$. 


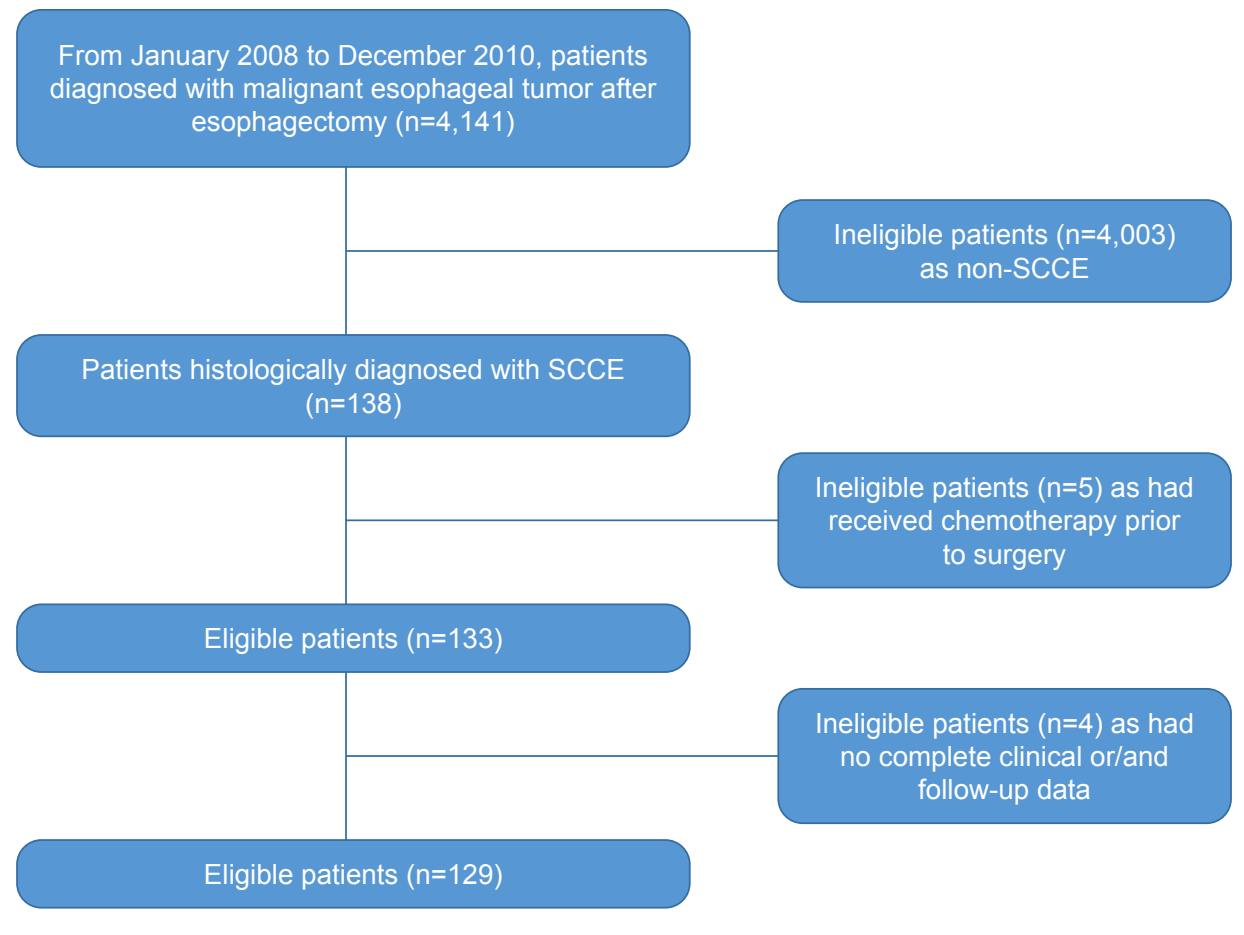

Figure I SCCE study flow diagram.

Abbreviation: SCCE, small-cell carcinoma of the esophagus.

The relationship between NLR and the clinicopathologic characteristics of the 129 patients with SCCE is shown in Table 1. This study showed that NLR was not associated with any clinicopathologic characteristic in list.

The median OS was 12 months (95\% CI: 10.9-13.1). The 1-, 3-, and 5-year survival rates were $51.2 \%, 34.1 \%$, and $13.2 \%$, respectively. Our univariate analysis showed that seven clinicopathologic variables, namely histology, tumor location and stage, nodal metastasis, TNM stage, adjuvant therapy, and NLR, were significantly associated with OS (Table 2, Figure 2). All of the confounding factors were then included in the multivariate Cox proportional hazards model (enter procedure) to adjust for the effects of covariates, which demonstrated that NLR was a valuable clinical marker in prognosis prediction for patients with primary SCCE (NLR $<2.97$ vs $\geq 2.97, P=0.004$, Table 3 ). The predictive effect of NLR on OS rate was further assessed after stratification by nodal metastasis staging. NLR was associated with clinical outcome only in patients with pN0 disease (Table 4). pN0 patients with an NLR $\geq 2.97$ had significantly worse OS (hazard ratio $(\mathrm{HR})=2.314 ; 95 \%$ CI: $1.401-3.822 ; P<0.001$ ) (Figure 3). No differences were observed in patients with other $\mathrm{pN}$ stages.

We then prepared multivariate models 1 (histology, tumor stage, TNM stage, and adjuvant therapy) and 2 (histology, tumor stage, TNM stage, adjuvant therapy, and NLR).
AIC was calculated for OS in these models to document the prognostic role (Table 5). The results from the AIC analysis suggest that model 2 gives a better prediction of survival in patients with SCCE.

\section{Discussion}

Inflammation plays an important role in the development and progression of various solid tumors. ${ }^{7,8,12,13}$ Inflammatory cells within the tumor microenvironment can enhance angiogenesis, invasion, motility, and viability. ${ }^{10,14,15}$ Cancer cells may also produce myeloid growth factors, such as granulocyte colony-stimulating factor, interleukin (IL)-1, IL-6, and tumor necrosis factor- $\alpha$. These growth factors contribute to the tumor-related leukocytosis and neutrophilia. ${ }^{16,17}$ Research has confirmed a link between the systemic inflammatory responses and the tumor inflammatory microenvironment. ${ }^{18,19}$ Therefore, measurements of systemic inflammation, including NLR, may reflect the degree of host inflammatory cell activity that promotes tumor growth and progression. Several research studies have reported that NLR and other similar measures have been associated with clinical outcomes after surgery for gastroesophageal cancer. ${ }^{20-24}$

To the best of our knowledge, this is the first study to show NLR as an independent prognostic factor in patients with SCCE. There was a study investigating the prognostic importance of NLR in 43 patients with SCCE. ${ }^{24}$ The area under the 
Table I General characteristics of patients according to NLR groups

\begin{tabular}{|c|c|c|c|c|}
\hline \multirow[t]{2}{*}{ Variables } & $\begin{array}{l}\text { Low-NLR } \\
\text { group }(n=56)\end{array}$ & $\begin{array}{l}\text { High-NLR } \\
\text { group }(n=73)\end{array}$ & $\chi^{2}$ value & $P$-value \\
\hline & Case, n (\%) & Case, n (\%) & & \\
\hline Sex & & & 1.350 & 0.245 \\
\hline Male & $40(71.4)$ & $45(6 I .6)$ & & \\
\hline Female & $16(28.6)$ & $28(38.4)$ & & \\
\hline Age* (years) & & & 0.034 & 0.853 \\
\hline$<60$ & $27(48.2)$ & $34(46.6)$ & & \\
\hline$\geq 60$ & $29(51.8)$ & $39(53.4)$ & & \\
\hline Histology & & & 0.252 & 0.615 \\
\hline SCCE & $36(64.3)$ & $50(68.5)$ & & \\
\hline $\begin{array}{l}\text { With squamous } \\
\text { cell carcinoma }\end{array}$ & $20(35.7)$ & $23(31.5)$ & & \\
\hline Tumor stage & & & 0.046 & 0.977 \\
\hline TI & $13(23.2)$ & I 8 (24.7) & & \\
\hline $\mathrm{T} 2$ & $16(28.6)$ & $21(28.8)$ & & \\
\hline T3 & $27(48.2)$ & $34(46.5)$ & & \\
\hline Tumor location & & & 0.120 & 0.942 \\
\hline Upper & $3(5.4)$ & $3(4.1)$ & & \\
\hline Middle & $45(80.4)$ & $59(80.8)$ & & \\
\hline Lower & $8(14.2)$ & II (I5.I) & & \\
\hline Nodal metastasis & & & 3.900 & 0.272 \\
\hline No & $37(66.1)$ & $47(64.4)$ & & \\
\hline $\mathrm{NI}$ & $13(23.2)$ & $21(28.8)$ & & \\
\hline N2 & $6(10.7)$ & $3(4.1)$ & & \\
\hline N3 & $0(0)$ & $2(2.7)$ & & \\
\hline TNM stage & & & 1.687 & 0.430 \\
\hline 1 & $19(33.9)$ & $29(39.7)$ & & \\
\hline ॥ & $27(48.2)$ & $27(37.0)$ & & \\
\hline III & $10(17.9)$ & $17(23.3)$ & & \\
\hline Perineural invasion & & & 1.385 & 0.239 \\
\hline Negative & $52(92.9)$ & 7I (97.3) & & \\
\hline Positive & $4(7.1)$ & $2(2.7)$ & & \\
\hline Vessel involvement & & & 1.558 & 0.212 \\
\hline Negative & $56(100)$ & 7I (97.3) & & \\
\hline Positive & $0(0)$ & $2(2.7)$ & & \\
\hline
\end{tabular}

Note: *Mean age.

Abbreviations: NLR, neutrophil/lymphocyte ratio; SCCE, small-cell carcinoma of the esophagus.

curve was 0.650 while that of the present study was 0.702 . Feng et $\mathrm{al}^{24}$ showed that NLR did not correlate with the prognostic factor in patients with SCCE and reported that survival rate did not differ according to NLR categories ( $\geq 3.5$ and $<3.5$ ). However, this study enrolled 129 consecutive patients to evaluate the role of NLR with other clinicopathologic features in the clinical outcome of patients with surgically resected SCCE and showed that a high preoperative NLR ( $\geq 2.97$ vs $<2.97, P=0.004$ ) was an indicator of poorer OS in patients with SCCE, independent of cancer stage, adjuvant therapy, and SCCE histologically with or without squamous cell carcinoma. These differences might due to a relatively larger sample in the study or a different cutoff value for NLR.

Several studies have shown NLR to be predictive of outcomes in ECs. ${ }^{25-29}$ However, the cutoff values for elevated
Table 2 Univariate analysis of prognostic factors of overall survival

\begin{tabular}{|c|c|c|c|c|c|}
\hline \multirow[t]{2}{*}{ Variables } & \multirow[t]{2}{*}{ Case (n) } & \multicolumn{3}{|c|}{ Survival rate (\%) } & \multirow[t]{2}{*}{$P$-value } \\
\hline & & I year & 3 years & 5 years & \\
\hline Sex & & & & & 0.606 \\
\hline Male & 73 & 52.9 & 34.1 & 14.1 & \\
\hline Female & 40 & 47.7 & 34.1 & 11.4 & \\
\hline Age* & & & & & 0.384 \\
\hline$<60$ & 61 & 54.1 & 39.3 & 14.8 & \\
\hline$\geq 60$ & 68 & 48.5 & 29.4 & 11.8 & \\
\hline Histology & & & & & 0.039 \\
\hline SCCE & 86 & 44.2 & 29.1 & 9.3 & \\
\hline $\begin{array}{l}\text { With squamous } \\
\text { cell carcinoma }\end{array}$ & 43 & 65.1 & 44.2 & 20.9 & \\
\hline Tumor stage & & & & & $<0.001$ \\
\hline $\mathrm{TI}$ & 31 & 83.9 & 54.8 & 32.3 & \\
\hline $\mathrm{T} 2$ & 37 & 51.4 & 35.1 & 10.8 & \\
\hline T3 & 61 & 34.4 & 23.0 & 4.9 & \\
\hline Tumor location & & & & & 0.026 \\
\hline Upper & 6 & 16.7 & 16.7 & 0 & \\
\hline Middle & 104 & 56.7 & 38.5 & 15.4 & \\
\hline Lower & 19 & 31.6 & 15.8 & 5.3 & \\
\hline Nodal metastasis & & & & & $<0.001$ \\
\hline No & 84 & 65.5 & 45.2 & 17.9 & \\
\hline $\mathrm{NI}$ & 34 & 29.4 & 14.7 & 5.9 & \\
\hline N2 & 9 & II.I & II.I & 0 & \\
\hline N3 & 2 & 0 & 0 & 0 & \\
\hline TNM stage & & & & & $<0.001$ \\
\hline I & 48 & 81.2 & 54.2 & 25.0 & \\
\hline II & 54 & 42.6 & 29.6 & 9.3 & \\
\hline III & 27 & 14.8 & 7.4 & 0 & \\
\hline Perineural invasion & & & & & 0.687 \\
\hline Negative & 123 & 51.2 & 34.1 & 13.0 & \\
\hline Positive & 6 & 50.0 & 33.3 & 16.7 & \\
\hline Vessel involvement & & & & & 0.572 \\
\hline Negative & 127 & 50.4 & 34.6 & 13.4 & \\
\hline Positive & 2 & 100 & 0 & 0 & \\
\hline Adjuvant therapy & & & & & $<0.001$ \\
\hline Chemotherapy & 80 & 67.5 & 46.3 & 18.7 & \\
\hline Radiochemotherapy & 49 & 24.5 & 14.3 & 4.1 & \\
\hline NLR & & & & & 0.002 \\
\hline Low & 56 & 57.1 & 50.0 & 23.2 & \\
\hline High & 73 & 46.6 & 21.9 & 5.5 & \\
\hline
\end{tabular}

Note: *Mean age.

Abbreviations: NLR, neutrophil/lymphocyte ratio; SCCE, small-cell carcinoma of the esophagus.

NLR varied in these studies. In these studies investigating NLR in EC, the cutoff value was mean/median value ${ }^{25,26}$ or was determined with ROC analysis ${ }^{27,28}$ or accepted as the cutoff value as in previous studies. ${ }^{29,30}$ The patients were classified according to a cutoff value (3.5) accepted as in a previous study by Feng et al, ${ }^{24}$ whereas in the present study, the cutoff value was determined by using the ROC analysis and it was calculated to be 2.97 by using a time-dependent ROC curve. With this cutoff value, nearly half of the patients were included in the high-NLR group. Therefore, this cutoff value is considered to be useful for predicting the prognosis after esophagectomy for patients with SCCE. We chose to 


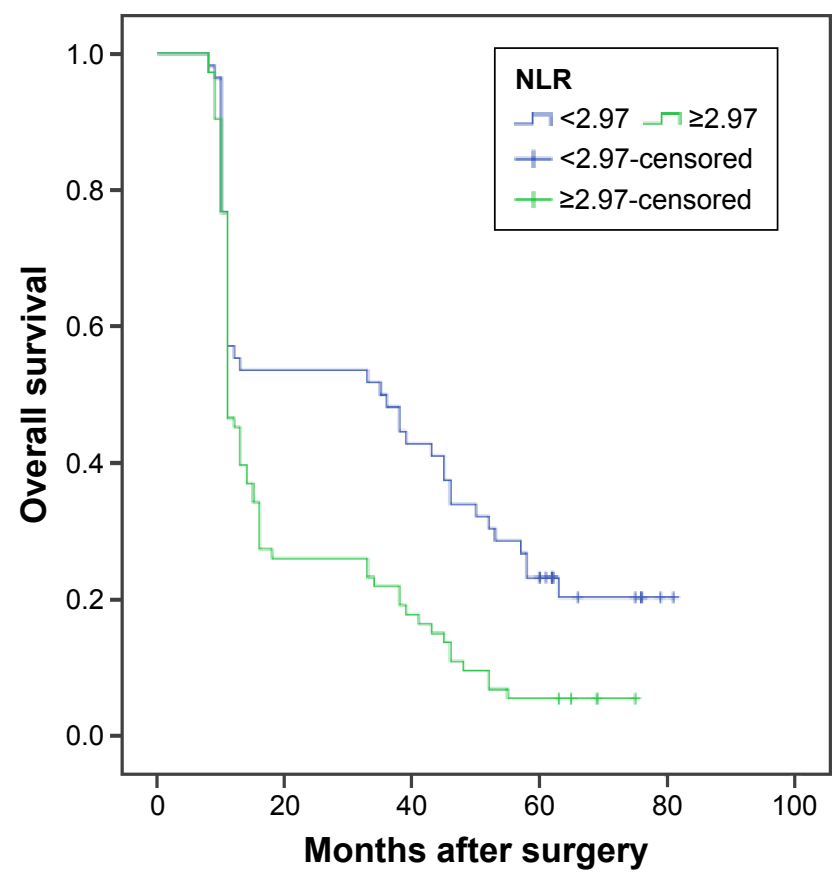

Figure 2 Kaplan-Meier analysis of NLR for OS in patents with SCCE. Abbreviations: NLR, neutrophil/lymphocyte ratio; OS, overall survival; SCCE, small-cell carcinoma of the esophagus.

dichotomize NLR as $\geq 2.97$ or $<2.97$ in order to be consistent with prior studies that had used the same method to determine the cutoff value ${ }^{27,28}$ and found that patients with higher NLRs $(\geq 2.97)$ had greater risk of death than those with lower NLRs (<2.97; HR: 1.803; 95\% CI: 1.203-2.702; $P=0.004)$. However, it is unclear whether a different cutoff value would serve as an even better predictor for survival rate, or NLRs categorized as "high," "intermediate," and "low" or in quartiles instead of dichotomized would be better.

This study suggested that the prognostic value of NLR in the pN0 group was more useful than that in the $\mathrm{pN} 1-\mathrm{pN} 3$ groups for risk stratification of patients with an elevated NLR level, but it was not satisfactory, due to the small sample in patients with $\mathrm{N} 2$ and $\mathrm{N} 3$ diseases. The data also showed that the number of lymph nodes dissected, of which the median was 8 (6-16) in this study, was sufficient for adequate nodal

Table 3 Multivariate survival analysis for various potential prognostic factors of overall survival

\begin{tabular}{llll}
\hline Variables & HR & $\mathbf{9 5 \%} \mathbf{C l}$ & $\boldsymbol{P}$-value \\
\hline Histology & 0.660 & $0.441-0.989$ & 0.044 \\
Tumor stage & 1.729 & $1.365-2.189$ & $<0.00 \mathrm{I}$ \\
Tumor location & 1.347 & $0.846-2.142$ & 0.209 \\
Nodal metastasis & 1.619 & $0.926-2.832$ & 0.091 \\
TNM stage & 1.642 & $1.071-2.518$ & 0.023 \\
Adjuvant therapy & 0.611 & $0.405-0.920$ & 0.018 \\
NLR & 1.803 & $1.203-2.702$ & 0.004 \\
\hline
\end{tabular}

Abbreviations: $\mathrm{Cl}$, confidence interval; $\mathrm{HR}$, hazard ratio; NLR, neutrophil/lymphocyte ratio.
Table 4 Univariate analysis of NLR stratified by nodal metastasis

\begin{tabular}{lllll}
\hline $\begin{array}{l}\text { Nodal } \\
\text { metastasis }\end{array}$ & Case (n) & $\begin{array}{l}\text { Median survival } \\
\text { time (months) }\end{array}$ & $\mathbf{9 5 \%} \mathbf{C l}$ & P-value \\
\hline pN0 & 84 & 18.0 & $0.853-35.147$ & $<0.001$ \\
Low NLR & 37 & 46.0 & $32.929-59.071$ & - \\
High NLR & 47 & 15.0 & $12.765-17.235$ & - \\
pNI & 34 & 11.0 & $10.566-11.434$ & 0.633 \\
Low NLR & 13 & 11.0 & $10.348-11.652$ & - \\
High NLR & 21 & 11.0 & $10.420-11.580$ & - \\
pN2 & 9 & 10.0 & $9.511-10.489$ & 0.739 \\
Low NLR & 6 & 10.0 & $9.404-10.596$ & - \\
High NLR & 3 & 10.0 & - & - \\
PN3 & 2 & 8.0 & - & - \\
Low NLR & 0 & - & - & - \\
High NLR & 2 & 8.0 & - & - \\
\hline
\end{tabular}

Abbreviations: $\mathrm{Cl}$, confidence interval; $\mathrm{NLR}$, neutrophil/lymphocyte ratio.

staging because the seventh edition of the International Union for Cancer Control and The American Joint Committee on Cancer $^{11}$ recommends that the number of lymph nodes resected be at least six for proper nodal classification, and at least seven lymph nodes must be removed to diagnose a patient as N3 (14 and 15, respectively, in this study).

AIC was calculated to document the importance of NLR in the multivariate models. Because AIC decreased with NLR in the multivariate model, it was assumed that NLR is a meaningful predictor of survival in patients with surgically treated primary esophageal small-cell carcinoma.

This study also has certain limitations. This was a retrospective study, and this study used data from a single

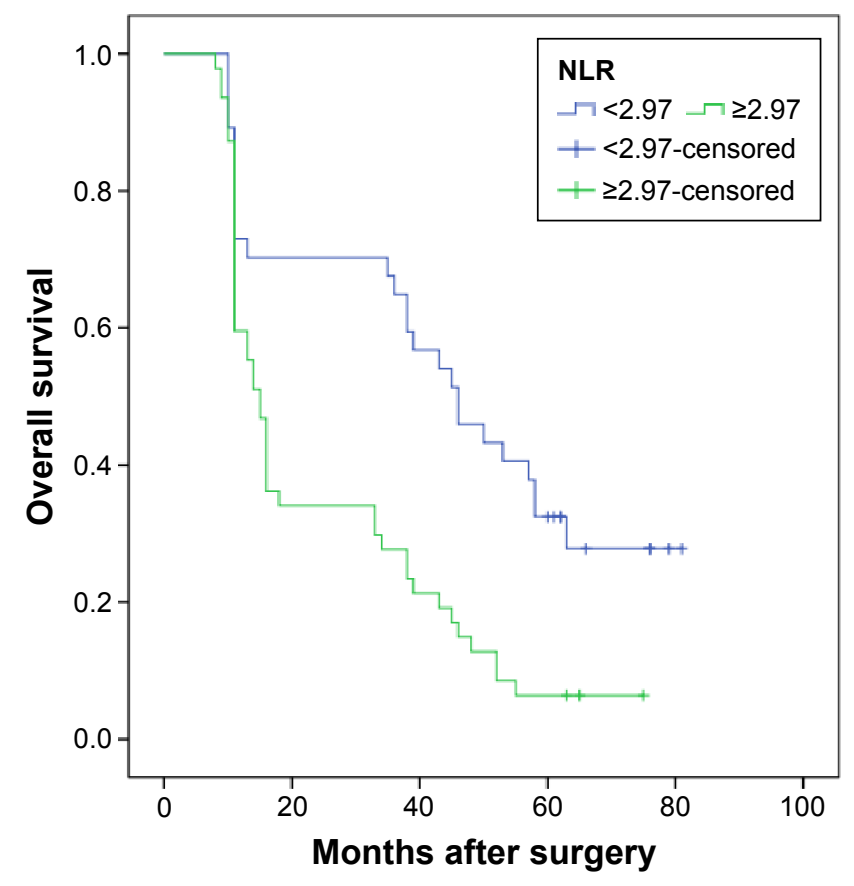

Figure 3 Kaplan-Meier analysis of NLR for OS in patents with pNO SCCE. Abbreviations: NLR, neutrophil/lymphocyte ratio; OS, overall survival; SCCE, small-cell carcinoma of the esophagus. 
Table 5 AIC results of the two multivariate models

\begin{tabular}{ll}
\hline Model & $\begin{array}{l}\text { Overall } \\
\text { survival }\end{array}$ \\
\hline I (histology, tumor stage, TNM stage, and adjuvant therapy) & 928.295 \\
2 (histology, tumor stage, TNM stage, adjuvant therapy, and & 923.222 \\
NLR) & \\
\hline
\end{tabular}

Abbreviations: AIC, Akaike information criterion; NLR, neutrophil/lymphocyte ratio.

institution. Therefore, prospective studies involving worldwide EC centers are recommended to confirm these results in a broader population.

In conclusion, preoperative NLR is significantly associated with clinical outcomes and could be used to stratify prognosis in patients with SCCE receiving surgical treatment. It can be easily obtained from a routine examination before surgery and does not require additional cost. Preoperative NLR may be taken into consideration for the prognosis of patients with SCCE.

\section{Disclosure}

The authors alone are responsible for the writing and content of this paper. The authors report no conflicts of interest in this work.

\section{References}

1. Wang HH, Zaorsky NG, Meng MB, et al. Multimodality therapy is recommended for limited-stage combined small cell esophageal carcinoma. Onco Targets Ther. 2015;8:437-444.

2. Purwar P, Jiwnani S, Karimundackal G, Pramesh CS. Management of esophageal small cell carcinoma. Ann Thorac Surg. 2015;99(4):1488.

3. Shen W, Deng W, Li N, Wei C, Luo S. Prognostic impact of different chemotherapy strategies on small cell esophageal carcinoma. Zhonghua Zhong Liu Za Zhi. 2015;37(10):780-783.

4. Duan H, Zhang X, Wang FX, et al. Prognostic role of neutrophil-lymphocyte ratio in operable esophageal squamous cell carcinoma. World J Gastroenterol. 2015;21(18):5591-5597.

5. Zhang J, Zhu Z, Liu Y, et al. Diagnostic value of multiple tumor markers for patients with esophageal carcinoma. PLoS One. 2015; 10(2):e0116951.

6. Han LH, Jia YB, Song QX, Wang JB, Wang NN, Cheng YF. Prognostic significance of preoperative lymphocyte-monocyte ratio in patients with resectable esophageal squamous cell carcinoma. Asian Pac J Cancer Prev. 2015;16(6):2245-2250.

7. Wei XL, Wang FH, Zhang DS, et al. A novel inflammation-based prognostic score in esophageal squamous cell carcinoma: the C-reactive protein/albumin ratio. BMC Cancer. 2015;15:350.

8. Kosumi K, Baba Y, Ishimoto T, et al. Neutrophil/lymphocyte ratio predicts the prognosis in esophageal squamous cell carcinoma patients. Surg Today. 2016;46(4):405-413.

9. Hirahara N, Matsubara T, Hayashi H, Takai K, Fujii Y, Tajima Y. Impact of inflammation-based prognostic score on survival after curative thoracoscopic esophagectomy for esophageal cancer. Eur J Surg Oncol. 2015;41(10):1308-1315.

10. Jung J, Park SY, Park SJ, Park J. Prognostic value of the neutrophil-tolymphocyte ratio for overall and disease-free survival in patients with surgically treated esophageal squamous cell carcinoma. Tumour Biol. 2016;37(6):7149-7154.

11. Sobin LH, Gospodarowicz MK, Wittekind C. TNM Classification of Malignant Tumors. 7th ed. Oxford: Wiley-Blackwell; 2010.
12. Liu JS, Huang Y, Yang X, Feng JF. A nomogram to predict prognostic values of various inflammatory biomarkers in patients with esophageal squamous cell carcinoma. Am J Cancer Res. 2015;5(7):2180-2189.

13. Arigami T, Okumura H, Matsumoto M, et al. Analysis of the fibrinogen and neutrophil-lymphocyte ratio in esophageal squamous cell carcinoma: a promising blood marker of tumor progression and prognosis. Medicine (Baltimore). 2015;94(42):e1702.

14. Shao Y, Ning Z, Chen J, et al. Prognostic nomogram integrated systemic inflammation score for patients with esophageal squamous cell carcinoma undergoing radical esophagectomy. Sci Rep. 2015;5:18811.

15. Wang J, Jia Y, Wang N, et al. The clinical significance of tumorinfiltrating neutrophils and neutrophil-to-CD8+ lymphocyte ratio in patients with resectable esophageal squamous cell carcinoma. J Transl Med. 2014;12:7.

16. Feng JF, Huang Y, Chen QX. Preoperative platelet lymphocyte ratio (PLR) is superior to neutrophil lymphocyte ratio (NLR) as a predictive factor in patients with esophageal squamous cell carcinoma. World $J$ Surg Oncol. 2014;12:58.

17. Kemal Y, Yucel I, Ekiz K, et al. Elevated serum neutrophil to lymphocyte and platelet to lymphocyte ratios could be useful in lung cancer diagnosis. Asian Pac J Cancer Prev. 2014;15(6):2651-2654.

18. Yuan D, Zhu K, Li K, Yan R, Jia Y, Dang C. The preoperative neutrophillymphocyte ratio predicts recurrence and survival among patients undergoing R0 resections of adenocarcinomas of the esophagogastric junction. J Surg Oncol. 2014;110(3):333-340.

19. Chen H, He J. Preoperative neutrophil-to-lymphocyte ratio as a prognostic predictor after radical resection of esophageal squamous cell carcinoma. Zhonghua Zhong Liu Za Zhi. 2014;36(4):294-297.

20. Wang Y, Wang Q, Zhang N, et al. Identification of microRNAs as novel biomarkers for detecting esophageal squamous cell carcinoma in Asians: a meta-analysis. Tumour Biol. 2014;35(11):11595-11604.

21. Feng JF, Huang Y, Chen QX. The combination of platelet count and neutrophil lymphocyte ratio is a predictive factor in patients with esophageal squamous cell carcinoma. Transl Oncol. 2014;7(5):632-637.

22. Xie X, Luo KJ, Hu Y, Wang JY, Chen J. Prognostic value of preoperative platelet-lymphocyte and neutrophil-lymphocyte ratio in patients undergoing surgery for esophageal squamous cell cancer. Dis Esophagus. 2016;29(1):79-85.

23. Noble F, Hopkins J, Curtis N, et al. The role of systemic inflammatory and nutritional blood-borne markers in predicting response to neoadjuvant chemotherapy and survival in oesophagogastric cancer. Med Oncol. 2013;30(3):596.

24. Feng JF, Huang Y, Zhao Q, Chen QX. Clinical significance of preoperative neutrophil lymphocyte ratio versus platelet lymphocyte ratio in patients with small cell carcinoma of the esophagus. ScientificWorldJournal. 2013;2013:504365.

25. Feng JF, Huang Y, Liu JS. Combination of neutrophil lymphocyte ratio and platelet lymphocyte ratio is a useful predictor of postoperative survival in patients with esophageal squamous cell carcinoma. Onco Targets Ther. 2013;6:1605-1612.

26. Sato H, Tsubosa Y, Kawano T. Correlation between the pretherapeutic neutrophil to lymphocyte ratio and the pathologic response to neoadjuvant chemotherapy in patients with advanced esophageal cancer. World J Surg. 2012;36(3):617-622.

27. Dutta S, Crumley AB, Fullarton GM, Horgan PG, McMillan DC. Comparison of the prognostic value of tumour- and patient-related factors in patients undergoing potentially curative resection of oesophageal cancer. World J Surg. 2011;35(8):1861-1866.

28. Sharaiha RZ, Halazun KJ, Mirza F, et al. Elevated preoperative neutrophil: lymphocyte ratio as a predictor of postoperative disease recurrence in esophageal cancer. Ann Surg Oncol. 2011;18(12):3362-3369.

29. Hirahara N, Matsubara T, Hayashi H, Takai K, Nakada S, Tajima Y. Prognostic importance of controlling nutritional status in patients undergoing curative thoracoscopic esophagectomy for esophageal cancer. Am J Ther. Epub 2016 Feb 5.

30. Rashid F, Waraich N, Bhatti I, et al. A pre-operative elevated neutrophil: lymphocyte ratio does not predict survival from oesophageal cancer resection. World J Surg Oncol. 2010;8:1. 
OncoTargets and Therapy

\section{Publish your work in this journal}

OncoTargets and Therapy is an international, peer-reviewed, open access journal focusing on the pathological basis of all cancers, potential targets for therapy and treatment protocols employed to improve the management of cancer patients. The journal also focuses on the impact of management programs and new therapeutic agents and protocols on

patient perspectives such as quality of life, adherence and satisfaction. The manuscript management system is completely online and includes a very quick and fair peer-review system, which is all easy to use. Visit http://www.dovepress.com/testimonials.php to read real quotes from published authors.

Submit your manuscript here: http://www.dovepress.com/oncotargets-and-therapy-journal 